\title{
Impact of density and special features of manufacturing process on drying of autoclaved aerated concrete masonry blocks
}

\author{
Sanita Rubene, Martins Vilnitis, Juris Noviks \\ Riga Technical university, Faculty of Civil Engineering
}

\begin{abstract}
Autoclaved aerated concrete (AAC) masonry blocks are construction material with high heat insulation parameters. In time of sustainable construction, this material can be used as a load bearing construction material for a range of buildings where it is necessary to obtain high heat insulation parameters of external delimiting constructions. The main problem of autoclaved aerated masonry constructions is the significant influence of relative humidity rate and its gradient on heat resistivity properties of the masonry constructions. Therefore it is important to monitor the drying process of AAC masonry constructions in order to avoid the sealing of moisture inside the masonry by early application of finishing layers on the construction. As there is a variety of manufacturers who offer AAC masonry blocks and the manufacturing process of the blocks slightly differ as well as the ingredients used for the manufacturing of the blocks this research has been done to determine the impact of manufacturing features and density of the blocks on their drying properties. The testing has been performed by non-destructive testing method electrical impedance spectrometry (EIS) In the paper, there are included results of research of correlation between EIS and moisture content rate in masonry blocks provided by different manufacturers. All used blocks are with similar material density. As a result of the research correlation formulas between saturation rate of the material and EIS measurement result have been established and a graph of humidity migration throughout the cross section of the masonry construction has been determined.
\end{abstract}

Keywords: autoclaved aerated concrete, electrical impedance spectrometry, humidity distribution, non-destructive testing.

\section{INTRODUCTION}

Autoclaved aerated concrete (AAC) masonry blocks are construction materials with high heat insulation parameters. In time of sustainable construction, this material can be used as a load bearing construction material for a range of buildings where it is necessary to obtain high heat insulation parameters of external delimiting constructions. The main problem of autoclaved aerated masonry constructions is the significant influence of moisture content rate and its gradient on heat resistivity properties of the masonry constructions. Therefore, it is important to monitor the drying process of autoclaved aerated concrete masonry constructions in order to avoid sealing of the moisture inside the masonry by early application of finishing layers on the construction. As there is a variety of manufacturers who offer autoclaved aerated concrete masonry blocks and the manufacturing process of the blocks slightly differ as well as the ingredients used for the manufacturing of the blocks this research has been done to determine the impact of manufacturing features and density of the blocks on their humidity transfer properties and drying properties. The measurements have been performed by nondestructive testing method - electrical impedance spectrometry (EIS). In the paper, there are included results of research of correlation between EIS and moisture content rate of masonry blocks provided by different manufacturers. All used blocks are with similar material density. As a result of the research correlation formulas between moisture content rate of the material and EIS measurement result have been established and a graph of humidity migration throughout the cross section of the masonry construction has been determined.

\section{HUMIDITY DISTRIBUTION IN AUTOCLAVED AERATED CONCRETE CONSTRUCTIONS}

Humidity distribution in AAC masonry construction depend on a range of different factors which include the technology of the manufacturing, ratio of the ingredients used for the material as well as the type and quality of the ingredients themselves. The porosity as well as the pores' structure and density of the AAC has significant impact on the drying properties of the material and its mass transfer properties. 
Humidity rate of the AAC masonry constructions has significant impact on its heat resistivity properties as well because heat transfer by conduction is affected by transfer of energy through molecular collision, therefore it follows that the thermal conductivity in liquids and solids is much greater than in gases (i.e. for water vapour at $10^{\circ} \mathrm{C}$ the conductivity $\lambda$ is $\approx 0.024$ $\mathrm{W} / \mathrm{mK}$, while for liquid water, the conductivity $\lambda$ is $\approx$ $0.6 \mathrm{~W} / \mathrm{mK}$ which is a factor 25 times greater) [1]. The Research of Barsotelli et.al [1] provides information that the porosity of the construction material has impact on its hygrometric properties and the research shows a low absorption velocity as a consequence of the large amount of macropores that slow down the capillary forces. Water vapour permeability is enhanced by the degree of connection among the pores and by the absence of condensation phenomena which are favoured by the presence of micropores. Therefore, a higher quantity of micropores should be envisaged favouring the condensation phenomena and hindering the water vapour diffusion.

The water transport phenomena are usually modelled by the diffusion type equation. The equation can have two basic forms. In the first case the driving potential at moisture transport is represented by the capillary pressure and the transport parameters in the equation are moisture capacity and moisture permeability, parameters as the moisture permeability and capacity can be modelled from the pore size distribution. In the second case the water flow driving potential is represented by the moisture content and the material transport parameter is the moisture diffusivity and the equation has so called diffusion form Bruce and Klute [2]. As the water transport parameters depend on the boundary conditions there is a difference between the moisture diffusivity during the water absorption, redistribution and drying.

In a case of drying the diffusivity is smaller (Kuenzel [3]). A detailed study on drying diffusivity and its determination is given by (Pel et al. [4-5]; Pel and Landman [6]) which present the approaches to diffusivity determination at the absorption and at the drying during different drying phases. $\mathrm{Vu}$ [29] realised the simulation experiments of drying process considering the variability of pore structure parameters expressed by theoretical pore size distributions and modelling the water transport coefficients of building materials represented as a bundle of capillaries, size distribution of which is based on their pore structure [7] .

These statements will be used and developed in the particular research in order to determine the differences of hygrometric properties for several types of AAC masonry blocks by a non-destructive testing method, which can be applied on site conditions.

\section{NON-DESTRUCTIVE METHODS FOR DETERMINATION OF HUMIDITY DISTRIBUTION IN MASONRY CONSTRUCTIONS}

AAC masonry constructions are widely used for construction of buildings therefore the main field of application for the humidity distribution measurements would be buildings in construction stage or habitable buildings. Therefore, nondestructive measurement methods for detection of humidity distribution throughout the cross section of the AAC masonry construction are preferable.

Researches have been performed in order to detect the credibility of non-destructive test methods for the detection of relative humidity rate in constructions (mostly in concrete). So far, several methods for nondestructive detection of humidity rate in concrete constructions have been discussed.

Gamma densitometry is a nondestructive testing method commonly used to control the density of civil engineering materials [8], [9].

The principle of this method is based on a beam of gamma rays emitted by radioactive source and passing through the concrete (Fig. 1). The relative intensity of the transmitted particles is related to the mass of the traversed material $\mathrm{m}_{\mathrm{c}}$, the mass variation of the traversed points can thus be measured. Since chemical evolutions do not lead to significant losses of mass, the mass variation in these beams stem solely from water evaporation; and can be interpreted as the profile of water content variations [8], [10].

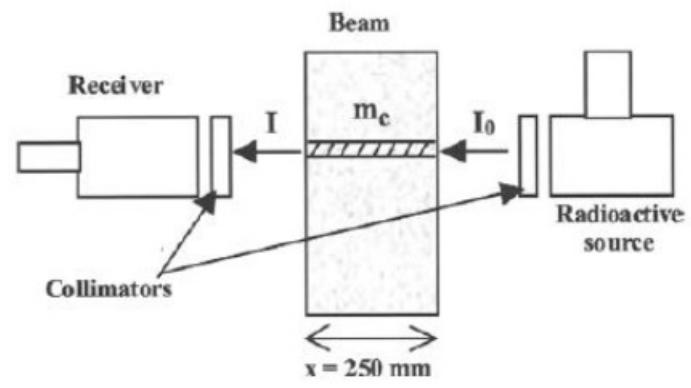

Fig. 1 Principle of the gamma densitometry technique [13], [15]

The gamma densitometry is based on absorption of the gamma ray emitted by a radioactive source of Cesium Cs137 [9]. The relation between intensity I of the flow of transmitted particles and traversed mass $m_{c}$ is as follows is based on the Lambert's Law [10].

The mass variation of the volume intercepted by the gamma ray can be measured at different depths, so water content variation along the height of the concrete beam's cross section can be monitored. The calculation method assumes that at each measurement the flow intercepts the same volume of material [8], [10].

This method allows determining humidity distribution throughout the height of the cross section by non-destructible method, but it can hardly be used 
in on-site conditions and is mostly laboratorial test method. Other restriction on this method is described in [8].

High quality relative humidity sensors are usually made of hair from horses or humans. The movement of the hair is converted into an electrical signal by a strain gauge. Similar sensors are made of a strip cellulose butyrate, a water absorbent polymer that likewise stretches and shrinks according to relative humidity.

There are two main types of relative humidity sensors, capacitive and resistive sensors. The capacitive sensor consists of a thin layer of water absorbent polymeric or inorganic material that is coated onto a conductive base. This layer is then covered with porous conductive layer material. With the increase of the relative humidity, the water content of the polymer increases too. Water has a high dielectric constant, which means that the combination of two electrodes with the water between can store a relatively high electric charge. This electrical capacity is measured by applying rapidly reversing (AC) voltage across the electrodes and measuring the current that passes. The polymer or inorganic material is usually aluminum oxide and just plays an indirect part of the measurement. The change of capacitance of these capacitive sensors is, however, small when even compared with the capacitance of few meters of cable. This means that the electronic process of data acquisition has to be completed close to the sensor. If one data logger is connected to several relative humidity sensors, each sensor will need its own power supply and relatively bulky electronics [8], [11].

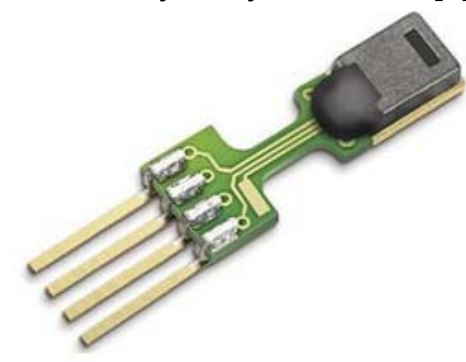

Fig. 2 (a) Capacitive sensor [8]

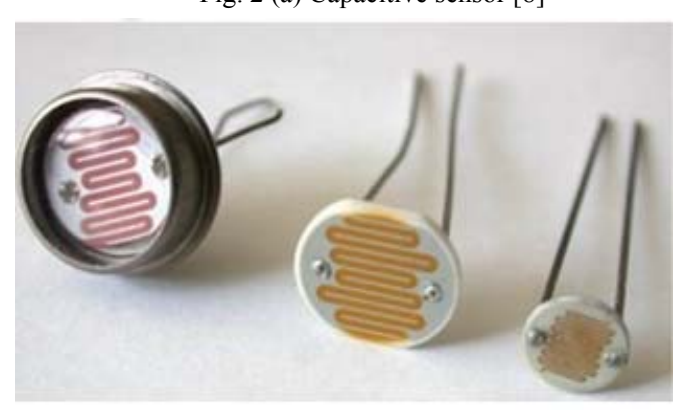

Fig. 2 (b) Resistivity Sensor [8]

Although capacitive sensors can have reduced accuracy at relative humidity values exceeding 90\%, they typically provide better linearity than resistive sensors. However, capacitive sensors can take several hours to reach equilibrium and provide valid readings [12]. They cannot also be directly exposed to fresh concrete. To solve this problem in the experiment, the sensors are mounted in plastic tubes with Gore-tex ${ }^{\circledR}$ caps and then embedded in fresh concrete. This material, protect the sensor from liquid water but allows vapor transmission. The vapor pressure within the airspace around the sensor and in the concrete pores will always be equal. This allowed the sensor to be permanently embedded in the concrete reaching its equilibrium and obtaining valid readings [8], [13].

Method of electrical impedance spectrometry (EIS) enables detection of the distribution of impedance or other electrical variables (such as resistivity, conductivity etc.) inside a monitored object, and thus the observation of its inner structure and its changes [14], [15]. This method ranks among indirect methods for detection of materials' properties through electrical measurements and it is used in measuring properties of organic and inorganic substances. So far, EIS is widely used in medicine as one of the most common testing methods in diagnostics where any kind of tissues are involved. It constitutes a very sensitive tool for monitoring phenomena that take place in objects (e.g. changes occurring in earth filled dams when loaded by water, in wet masonry sediments etc.), electrokinetic phenomena at boundaries (e.g. electrode/soil grain, between soil grains) or for describing basic ideas about the structure of an inter phase boundary (e.g. electrode/water) [16].

Rajabipour and Weiss have performed series of humidity detection and moisture gradient researches by application of EIS method [17]. The EIS method is based on the principle that a change in the water content of concrete alters the electrical response of the concrete (McCarter and Garvin [14], Weiss et al. [18]). On the other hand, Schieß1 and co-workers [19] have researched the moisture gradients that develop in drying concrete. Using a series of embedded stainless steel electrodes, they measured the electrical resistance of drying mortar samples as a function of distance from the drying surface [17]. As it is known from the approach of Matiasovsky, Mihalka, Pel, Landman [4-7] the water absorption, absorption after rewetting and the drying process have slightly different kinetics and should be considered separately.

EIS method with Z-meter [20] device allows using only one probe pair for multiple in-field measurements because the probes can be withdrawn from the construction after the measurement. Experiments with EIS method for the detection of humidity distribution throughout cross section of aerated concrete constructions have been performed in Riga Technical university by Z-meter III device and methodology for measurement process is being developed [21-23]. EIS method can be applied for non-destructive detection humidity level throughout 
aerated concrete constructions. It is easily applicable for testing of relative changes of humidity level in construction. In such cases no prior calibration of the Z-meter III device is necessary [24].

The research performed by the authors display the influence of different aspects of the manufacturing process of AAC masonry blocks on their drying properties in aspect of hygrometrics.

\section{DESCRIPTION OF THE EXPERIMENT}

For the particular experiment, a set of five different types of AAC masonry blocks were used (Table 1).

TABLE 1

TECHNICAL DATA OF AAC MASONRY BLOCKS USED FOR EXPERIMENT [25-28]

\begin{tabular}{ccc}
\hline $\begin{array}{c}\text { AAC block } \\
\text { figure }\end{array}$ & $\begin{array}{c}\text { Thermal } \\
\text { conductivity in } \\
\text { dry state stated } \\
\text { by manufacturer } \\
\lambda \mathrm{W} / \mathrm{mK}\end{array}$ & $\begin{array}{c}\text { Bulk density } \\
\text { stated by } \\
\text { manufacturer } \\
\mathrm{kg} / \mathrm{m}^{3}\end{array}$ \\
\hline A & 0,090 & 375 \\
B & 0,105 & 375 \\
C & 0,11 & 500 \\
D & 0,12 & 500 \\
E & 0,096 & 400 \\
\hline
\end{tabular}

There were chosen specimen with density in range from 375 to $500 \mathrm{~kg} / \mathrm{m}^{3}$ in order to determine the impact of density on speed of drying as well as on the accuracy of the EIS measurement results.

For the experiment a set of AAC masonry block samples were prepared, where four blocks of each type were taken. In each sample two bores were made for embedment of measurement probes (Fig.3).

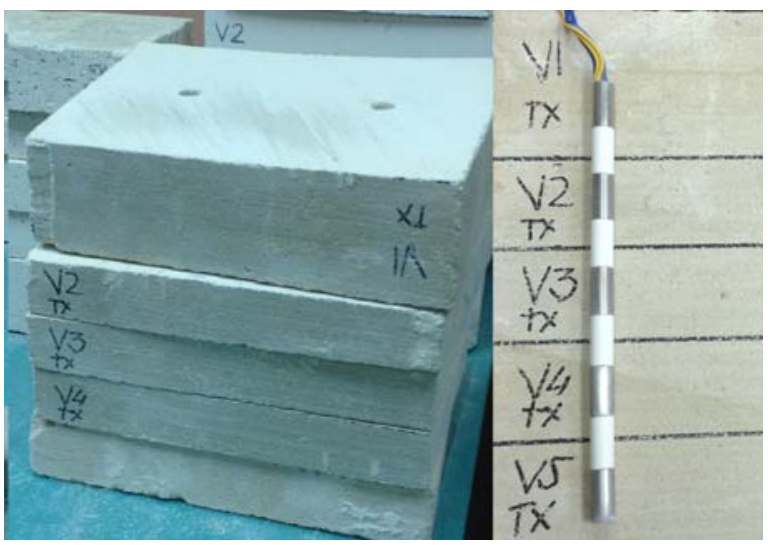

Fig.3 Autoclaved aerated masonry block sample with measurement probes

As the first step of the experiment the frequency analysis was performed on all samples in order to determine suitable EIS measurement frequency for all ACC masonry block types. The results of frequency analysis showed that there are different ranges of frequencies which should be used for the EIS measurements on each type of the samples. But in order to acquire comparable data same frequency had to be chosen for all samples. So it was determined, that the frequency of $8000 \mathrm{~Hz}$ is the most suitable for measurements on all samples.

One of the blocks from each type were split into several pieces according to the approach of Akita et al. [30] in order to determine the humidity rate of each segment in the masonry block by gravimetric method (Fig.4). The monitoring of the changes in humidity content of each sample was made by monitoring of mass changes in time for each specimen. Such approach allowed to determine the changes of moisture content in the samples.

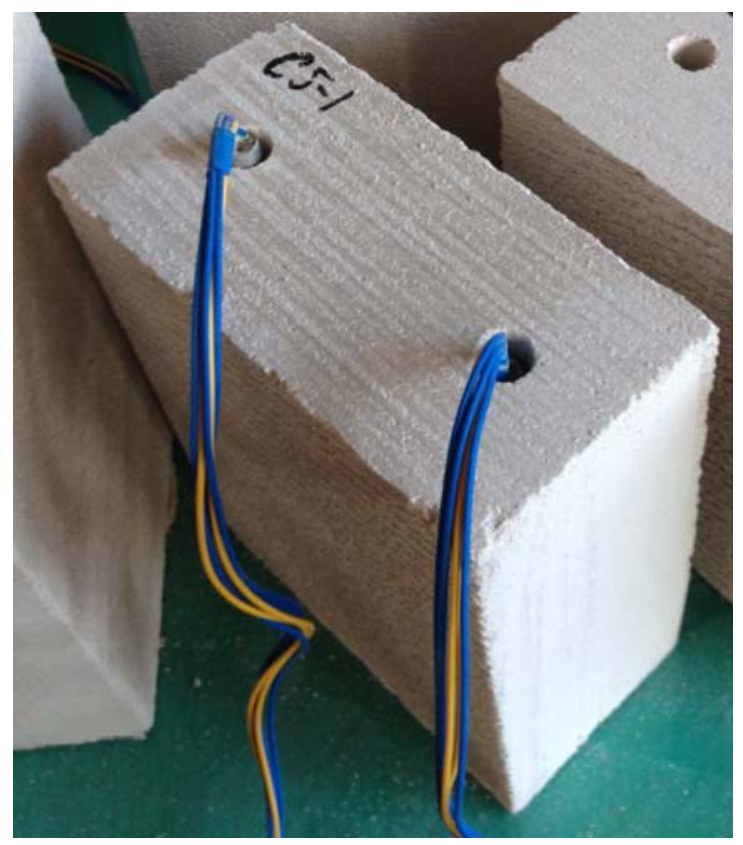

Fig.4 AAC masonry block samples for determination of humidity distribution by gravimetric method

The other three samples from each type were placed in laboratory premises $\left(20^{\circ} \mathrm{C}, 85 \% \mathrm{Rh}\right)$ for drying. Along the drying process regular EIS measurements were performed on all the experimental samples. Additional EIS measurements were performed on the cut samples in order to secure the obtained data of AAC masonry block relative humidity. Monitoring of samples` natural drying process was performed for four months. After the samples had reached the air dry state they were oven dried in order to determine the weight of samples in absolute dry state.

\section{RESULTS}

From the obtained results it can be concluded that the density of the AAC does not have significant impact on samples' drying speed. The C and D samples (Table 1) had lost approximately the same 
amount of moisture content (after 3 months of drying time in laboratory storage) in $\%$ as the other samples.

In the beginning of the experiment all samples had similar humidity distribution throughout the cross section although the humidity rate in the samples was significantly different (Fig.5). The initial humidity content of the AAC blocks depend on the specialties of the manufacturing process and storage conditions prior delivering the blocks to the construction site.

The data for Fig.5 was obtained by gravimetric measurement method for detection of moisture content in construction materials by the approach described by Akita et.al [30] and humidity content measurements by differences in mass. Further data concerning the moisture distribution throughout the cross section of the samples were obtained by EIS measurements. The gravimetric method was used for overall control of the experiment results and for preparation of correlation equation between the EIS measurement results and corresponding relative moisture content of the AAC.

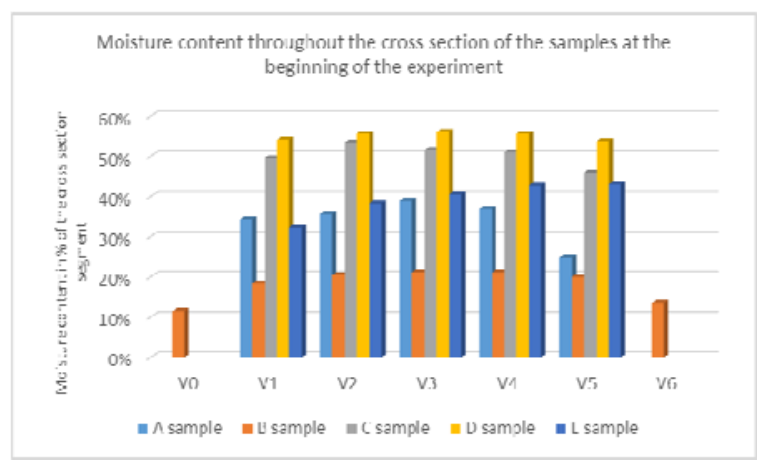

Fig.5 Moisture content throughout the cross section of the samples at the beginning of the experiment

In order to correlate values of EIS measurements with the absolute values of moisture content in cross section of the sample correlation graphs were prepared for each type of AAC samples (Fig.6a, 6b, 6c, 6d, 6e).

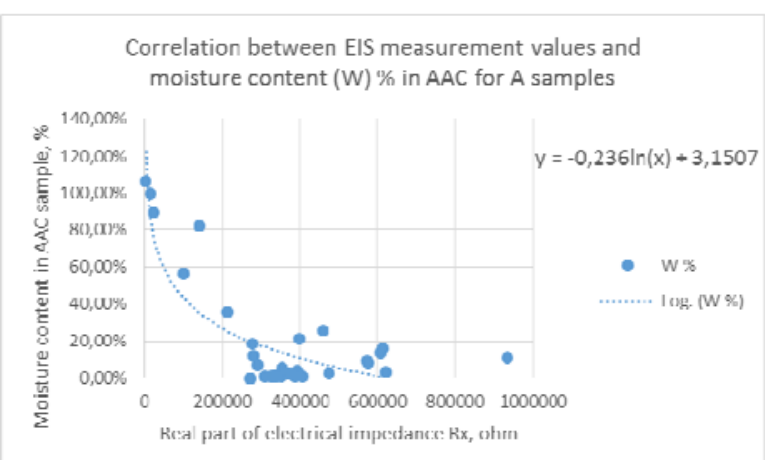

Fig.6a Correlation between EIS measurement values and moisture content of the samples of A series in \%

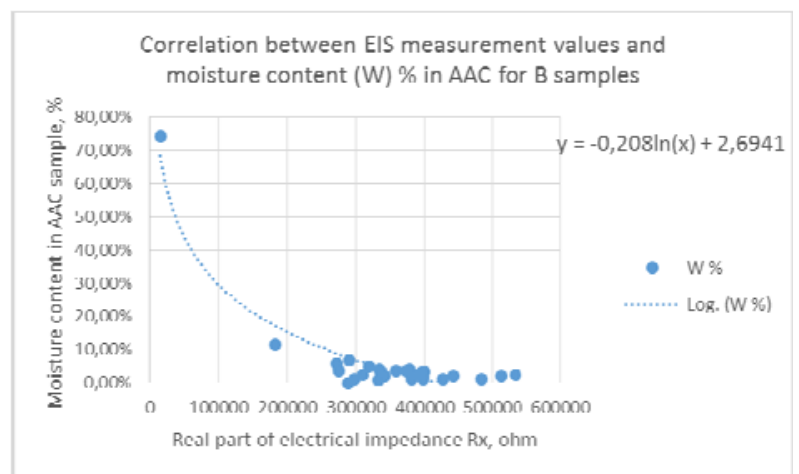

Fig.6b Correlation between EIS measurement values and moisture content of the samples of B series in \%

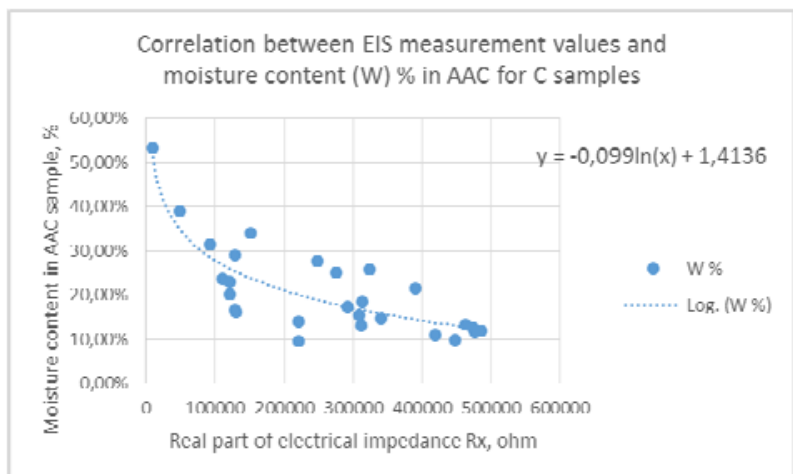

Fig.6c Correlation between EIS measurement values and moisture content of the samples of $\mathrm{C}$ series in \%

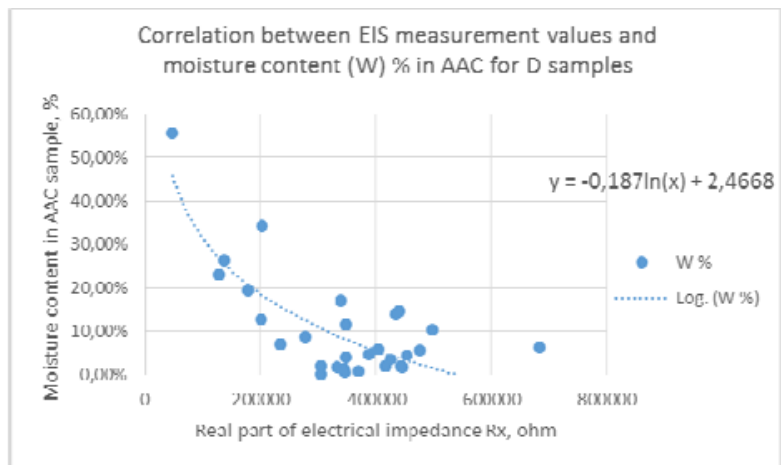

Fig.6d Correlation between EIS measurement values and moisture content of the samples of D series in \%

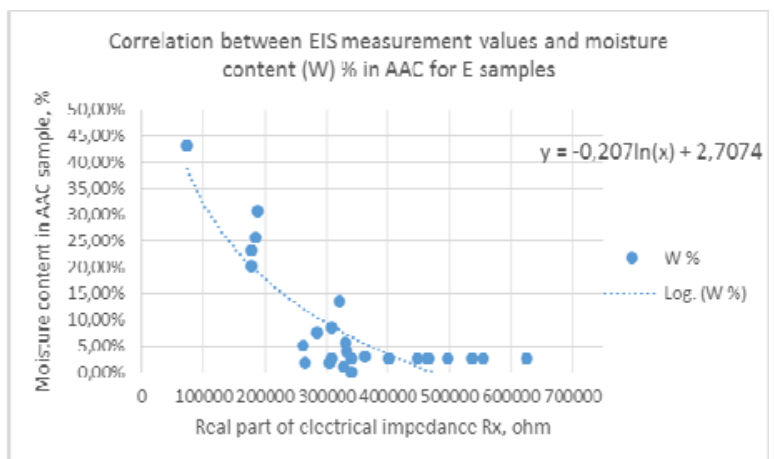

Fig.6e Correlation between EIS measurement values and moisture content of the samples of E series in \% 

form:

The correlation equations have the same basic

$$
\mathrm{y}=\mathrm{a} \ln (\mathrm{x})+\mathrm{C}
$$

where a varies from $-0,099$ to $-0,236$ and constant $\mathrm{C}$ varies from 1,4136 to 3,1507 . A and $\mathrm{C}$ values from each particular equation can be used as a describing parameters of the respective type of AAC in aspect of drying speed and interaction with EIS measurement method.

The equation data (Fig.6a to 6e) was used to determine the changes of moisture content throughout the cross section of the AAC samples after 3 months drying time (Fig.7).

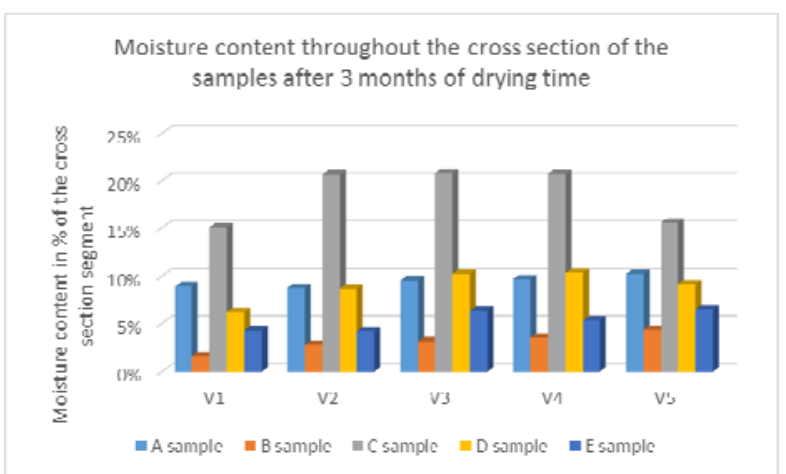

Fig.7 Moisture content throughout the cross section of the samples after 3 months of drying time

The measurement results show that the blocks with lower density have more regular humidity distribution throughout the cross section of the block than the samples with higher density.

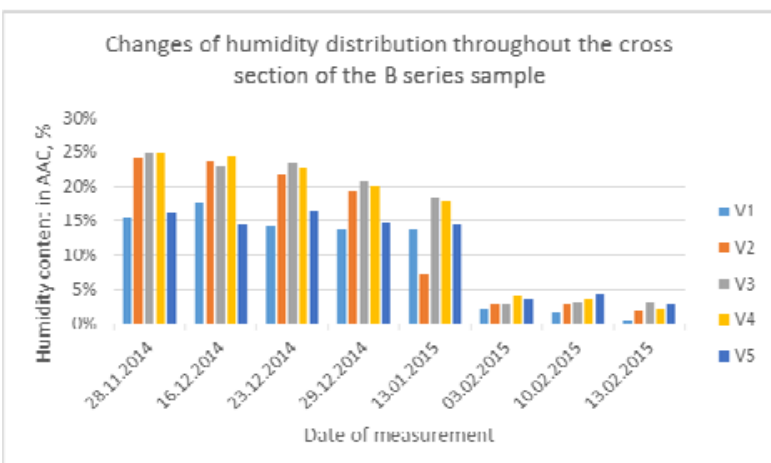

Fig.8 Changes of moisture content throughout the cross section of the samples during drying process

EIS measurement results can be transformed into moisture content rate of the AAC material and in such way the distribution of moisture content in the material sample can be determined by non-destructive method (Fig.8).

\section{CONCLUSIONS}

From the obtained results, it can be concluded that the density of the AAC does not have significant impact on overall speed of samples' drying. It has impact on the speed of drying only in case the sample has high moisture content which is above $40 \%$. In such case samples with higher density has lower drying speed for the central part of sample's cross section material.

However, the AAC density and structure of pores has significant impact on accuracy of EIS measurement interpretation. Therefore, prior using the EIS method by Z-meter device for humidity content measurements on-site, correlation equations between EIS measurement results and humidity content of the AAC sample should be determined in laboratory.

\section{REFERENCES}

[1] M. Barsottelli, G. F. Cellai, F. Fratini I and C. Manganelli Del Fa. The hygrometric behaviour of some artificial stone materials used as elements of masonry walls. Materials and Structures/Mat6riaux et Constructions, Vol. 34, May 2001, pp 211-216.

[2] Bruce RR, Klute A The measurement of soil moisture diffusivity. Soil Sci Soc Am Proc, 1956, pp:458-462.

[3] Kuenzel HM. Simultaneous heat and moisture transport in building components. IRB Verlag, Stuttgart, 1995.

[4] Pel L, Brocken H, Kopinga K. Determination of moisture diffusivity in porous media using moisture concentration profiles. Int J Heat Mass Transf 39, 1996, pp:1273-1280

[5] Pel L, Landman KA, Kaasschieter EF. Analytic solution for the non-linear drying problem. Int $\mathrm{J}$ Heat Mass Transf 45, 2002. pp:3173-3180.

[6] Pel L, Landman KA. A sharp drying front model. Drying Technol 22. 2004. pp:637-647

[7] Matiasovsky P., Mihalka P. Pore Structure Parameters and Drying Rates of Building Materials. J. M. P. Q. Delgado (ed.), Drying and Wetting of Building Materials and Components, Building Pathology and Rehabilitation 4, DOI: 10.1007/978-3319-04531-3 4, (C) Springer International Publishing Switzerland 2014, pp. 71-90.

[8] G.Quincot, M.Azenha, J. Barros, R.Faria. " State of the art Methods to measure moisture in concrete" Projetos De Investigação Científica E Desenvolvimento Tecnológico, Portugal, 2011.

[9] Villain, G. and M. Thiery. "Gammadensimetry: A method to determine drying and carbonation profiles in concrete." NDT \& E International 39(4), 2006. p.328-337.

[10] S. Multon, E. M. "Water distribution in beams damaged by alkali-silica reaction: global weighing and local gammadensitometry." Materials and Structures Vol. 37, 2004.

[11] Physics, C. "Relative humidity sensors" 2010: 1-3.

[12] Wiederhold, P. R. "Water vapor measurement, methods, and instrumentation." Marcel Dekker, Inc. New York, 1997. p. 384.

[13] Zachary Grasley, D. A. L. "Relative humidity in concrete." ACI Committee 236, 2006. p.51-57.

[14] McCarter, W.J.; Garvin, S. Dependence of Electrical Impedance of Cement-Based Materials on their Moisture Condition. In: Journal of Applied Physics Series D: Applied Physics 22 (1989), No. 11, S. 1773-1776.

[15] Elsener, B. Ion Migration and Electric Conductivity in Concrete. Zürich: SchweizerischerIngenieur- und ArchitektenVerein, 1990. - In: Korrosion und Korrosionsschutz. T1 5. Electrochemical Protection Process for Concrete Building Structures, Symposium 15. November 1990, S. 51-59. 
[16] Skramlik, J., Novotny, M.. One-dimensional moisture transport monitored by a non-destructive method. International Journal of Computers Issue 4, Volume 2, 2008.

[17] Farshad Rajabipour, Jason Weiss, John D. Shane, Thomas O. Mason, and Surendra P. Shah. A PROCEDURE TO INTERPRET ELECTRICAL CONDUCTIVITY MEASUREMENTS IN COVER CONCRETE DURING REWETTING. Journal of Materials in Civil Engineering, 2005. 17(5), pp:586-594.

[18] Weiss, W. J., Shane, J. D., Mieses, A., Mason, T. O., and Shah, S. P. Aspects of monitoring moisture changes using electrical impedance spectroscopy. Proceedings of the 2 nd Symposium on Self-Desiccation and Its Importance in Concrete Technology, Lund, Sweden. 1999.

[19] Schieß1, A., Weiss, W. J., Shane, J. D., Berke, N. S., Mason, T. O., and Shah, S. P. Assessing the moisture profile of drying concrete using impedance spectroscopy. Concrete Science and Engineering, 2, 2002. pp:106-116.

[20] Parilkova, J. The EIS Method and a Z-meter III Device, a lecture within an event in Litice.

[21] Rubene S. et al. Determination of Humidity Level in Aerated Concrete Constructions by Non Destructive Testing Methods, in Proc "Innovative Materials, Structures and Technologies" Riga, 2014 p.135-140.

[22] Rubene S., Vilnitis M. Application of Electrical Impedance Spectrometry for Determination of Moisture Distribution in Aerated Concrete Constructions in Proc. "1st Conference and Working Session Eureka! 7614” Brno, Czech Republic, 2013. p. 124-130.Rubene, S., Vilnītis, M., Noviks, J. Monitoring of the Aerated Concrete Construction Drying Process by Electrical Impedance Spectrometry. In: Proceedings of 4th International Conference "Advanced Construction 2014", Lithuania, Kaunas, 9-10 October, 2014. Kaunas: Kaunas University of Technology, 2014, pp.216-220. ISSN 20291213.

[23] Rubene, S., Vilnītis, M., Noviks, J. Impact of Masonry Joints on Detection of Humidity Distribution in Aerated Concrete Masonry Constructions by Electric Impedance Spectrometry Measurements. International Journal of Civil, Architectural, Structural and Construction Engineering, 2015, Vol.9, No.1, pp.1089-1094. e-ISSN 1307-6892.

[24] http://aeroc.lv/index.php?page=938\&lang=lat\&cnt=AEROC Universal site accessed on 17.03.2015.

[25] http://www.ytong-silka.pl/ru/content/756.php site accessed on 17.03 .2015

[26] http://www.texoblock.lv/upload/buklets_lv.pdf site accessed on 17.03.2015

[27] http://roclite.lv/v2/tehniskie-parametri/fiziskas-un-tehniskasipasibas/ site accessed on 17.03.2015

[28] $\mathrm{Vu} \mathrm{TH}$. Influence of pore size distribution on drying bahaviour of porous media by a vontinuous model. $\mathrm{PhD}$ thesis, Otto von Guericke University, Magdeburg. 2006.

[29] Akita, H., Fujiwara, T. and Ozaka, Y.." A practical procedure for the analysis of moisture transfer within concrete due to drying." Magazine of Concrete Research 48 (6), 1996, p.129137. 